TABLE 1. Values of preoperative and postoperative echocardiography (postoperative day 4) and cardiac magnetic resonance imaging (postoperative day 12)

\begin{tabular}{llcc}
\hline & & $\begin{array}{c}\text { Preoperative } \\
\text { value }\end{array}$ & $\begin{array}{c}\text { Postoperative } \\
\text { value }\end{array}$ \\
\hline Echocardiography & LVEF $(\%)$ & 20.5 & 47 \\
& LVIDd (mm) & 37.4 & 36 \\
Cardiac MRI & LVEF $(\%)$ & 14.2 & 35.8 \\
& LVEDV (mL) & 121.6 & 87.2 \\
& CO (L/min) & 1.82 & 2.59 \\
& RVEDV (mL) & 528.3 & 146 \\
\hline
\end{tabular}

$L V E F$, Left ventricular ejection fraction; $L V I D d$, left ventricular internal diastolic diameter; $L V E D V$, left ventricular end-diastolic volume; $C O$, cardiac output; $R V E D V$, right ventricular end-diastolic volume; $M R I$, magnetic resonance imaging.

from the $67 \%$ preoperative value to $54 \%$. Postoperative echocardiography revealed no paradoxical motion of the interventricular septum and a left ventricular ejection fraction of $47 \%$. Cardiac magnetic resonance imaging revealed a left ventricular ejection fraction of $35.8 \%$ and left ventricular end-diastolic volume of $124.6 \mathrm{~mL}$ (Figure 2). There was no arrhythmia on 24-hour Holter monitor. Eight months after the operation, the patient was in New York Heart Association functional class I with digoxin and angiotensin-converting inhibitor medication. Measured values by echocardiography and cardiac magnetic resonance imaging are shown in Table 1.

\section{CONCLUSIONS}

In this case, the right ventricular exclusion procedure not only normalized paradoxical interventricular septal motion but also increased effective volume loading of the left ventricle. The postoperative measured ratio $(0.62 \mathrm{~g} / \mathrm{mL})$ of left ventricular mass to left ventricular end-diastolic volume, which was normalized by body surface area, increased more than the preoperative measured ratio $(0.41$ $\mathrm{g} / \mathrm{mL}$ ). As a result, left ventricular ejection fraction improved. The right ventricular exclusion procedure may be effective for repairing arrhythmia by resecting the arrhythmogenic dysplastic and dilated right ventricle. As in this case, the right ventricular exclusion procedure may be a good option for severe congestive right ventricular failure of Ebstein's anomaly.

\section{References}

1. Kumar AE, Flyer DC, Miettinen OS, Nadas AS. Ebstein's anomaly: clinical profile and natural history. Am J Cardiol. 1971;28:84-95.

2. Starnes VA, Pitlick PT, Bernstein D, Griffin ML, Choy M, Shumway NE. Ebstein's anomaly appearing in the neonate: a new surgical approach. J Thorac Cardiovasc Surg. 1991;101:1082-7.

3. Sano S, Ishino K, Kawada M, Kasahara S, Kohmoto T, Takeuchi M, et al. Total right ventricular exclusion procedure: an operation for isolated congestive right ventricular failure. J Thorac Cardiovasc Surg. 2002;123:640-7.

\title{
Use of moldable titanium bars and rib clips for total sternal replacement: A new composite technique
}

\author{
Alessandro Gonfiotti, MD, ${ }^{\mathrm{a}}$ Paolo Ferruccio Santini, MD, ${ }^{\mathrm{a}}$ Domenico Campanacci, MD, ${ }^{\mathrm{b}}$ \\ Marco Innocenti, MD, ${ }^{\mathrm{c}}$ Sante Ferrarello, MD,${ }^{\mathrm{d}}$ and Alberto Janni, MD, ${ }^{\mathrm{a}}$ Florence, Italy
}

After a total sternectomy, a rigid prosthetic replacement is usually recommended to protect the lungs, heart, and main vessels and to prevent paradoxical respiration. ${ }^{1}$ The most common system used for rigid reconstruction of the sternum is methyl methacrylate, which is difficult to handle and mold

From the Thoracic Surgery Unit, ${ }^{\mathrm{a}}$ Orthopedic Oncology, ${ }^{\mathrm{b}}$ Plastic Surgery, ${ }^{\mathrm{c}}$ and Anesthesiology Unit, ${ }^{\mathrm{d}}$ University Hospital Careggi, Florence, Italy.

Received for publication July 14, 2008; revisions received Sept 4, 2008; accepted for publication Sept 14, 2008; available ahead of print Dec 1, 2008.

Address for reprints: Alessandro Gonfiotti, MD, Thoracic Surgery Unit, Azienda Ospedaliero-Universitaria Careggi, Viale Pieraccini n17, 50100, Firenze, Italy

(E-mail: agonfiotti@alice.it).

J Thorac Cardiovasc Surg 2009;138:1248-50

$0022-5223 / \$ 36.00$

Copyright $\odot 2009$ by The American Association for Thoracic Surgery

doi:10.1016/j.jtcvs.2008.09.034 into the correct shape. ${ }^{2}$ We describe a rigid sternal reconstruction after total sternectomy using a new system with moldable titanium bars and rib clips.

\section{CLINICAL SUMMARY}

A 65-year-old woman was admitted to our unit for a large and palpable chondrosarcoma of the sternum. The computed tomogram confirmed a lesion occupying the whole sternal body along with invasion of the manubrium (Figure 1, A), and a positron emission tomogram revealed a strong accumulation in the lesion, without accumulation elsewhere in the body. On this basis we performed a total sternectomy, including the entire sternum together with the previous site of biopsy, costochondral arches, and internal third of clavicles, 

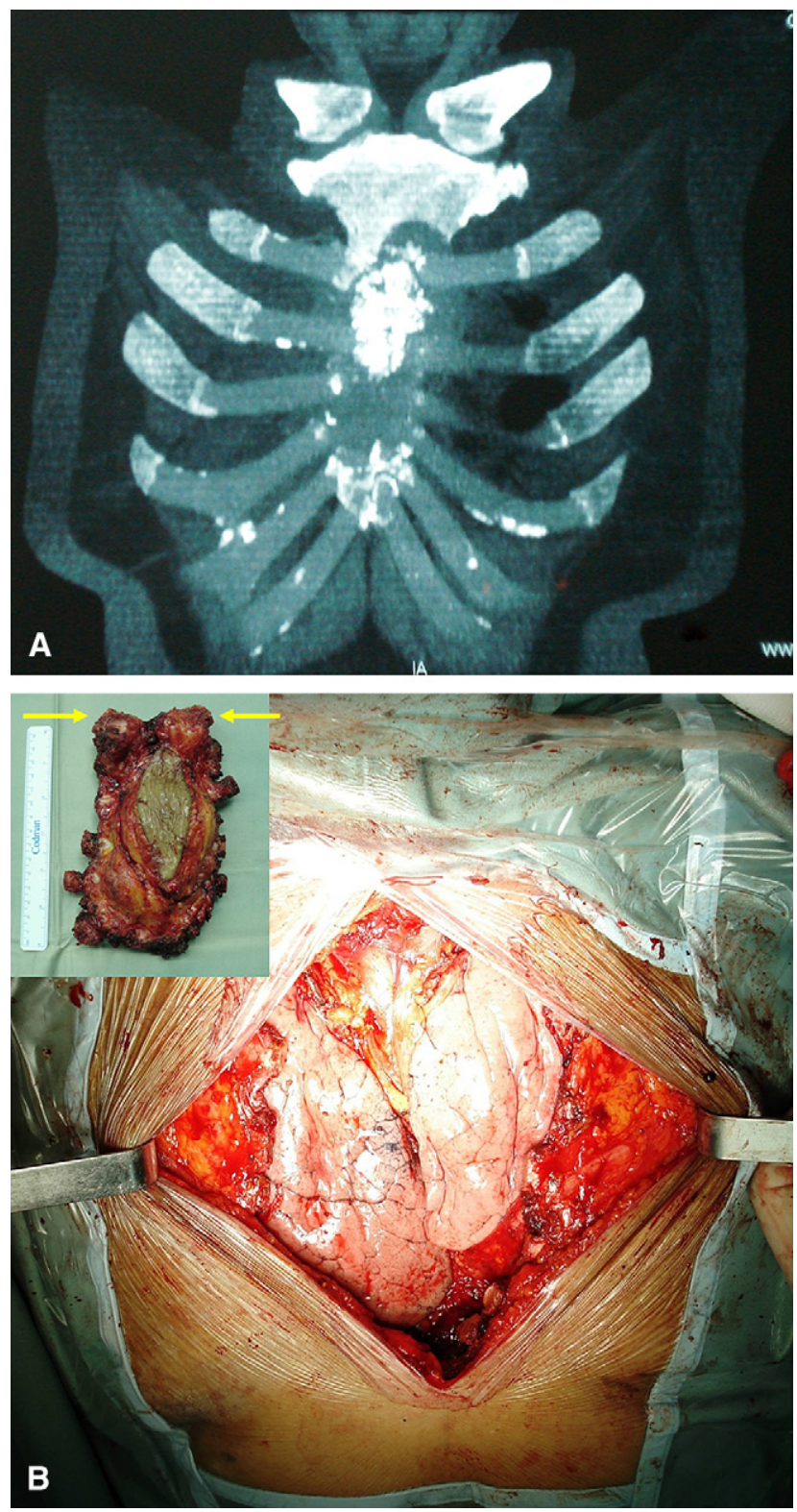

FIGURE 1. A, Preoperative computed tomogram of the chest showing a large chondrosarcoma of the sternal body envolving also the manubrium. $\mathrm{B}$, Intraoperative view of the wound site after resection with the sternum totally removed together with the previous site of biopsy, costochondral arches, and internal third of clavicles (arrows).

with healthy margins of at least $3 \mathrm{~cm}$ (Figure $1, B$ ). After resection, an expanded polytetrafluoroethylene (PTFE) patch 0.1-mm thick (Peritoneal; W. L. Gore \& Associates, Inc, Flagstaff, Ariz) was anchored to the inner edges of the defect with nonabsorbable suture to separate the mediastinum from the superficial layers; then a rigid sternal reconstruction was performed with titanium plates. For transverse reconstruction, we used the Strasbourg Thoracic Osteosyntheses System (STRATOS; MedXpert GmbH, Heitersheim, Germany); it consists of titanium rib clips available in differ-
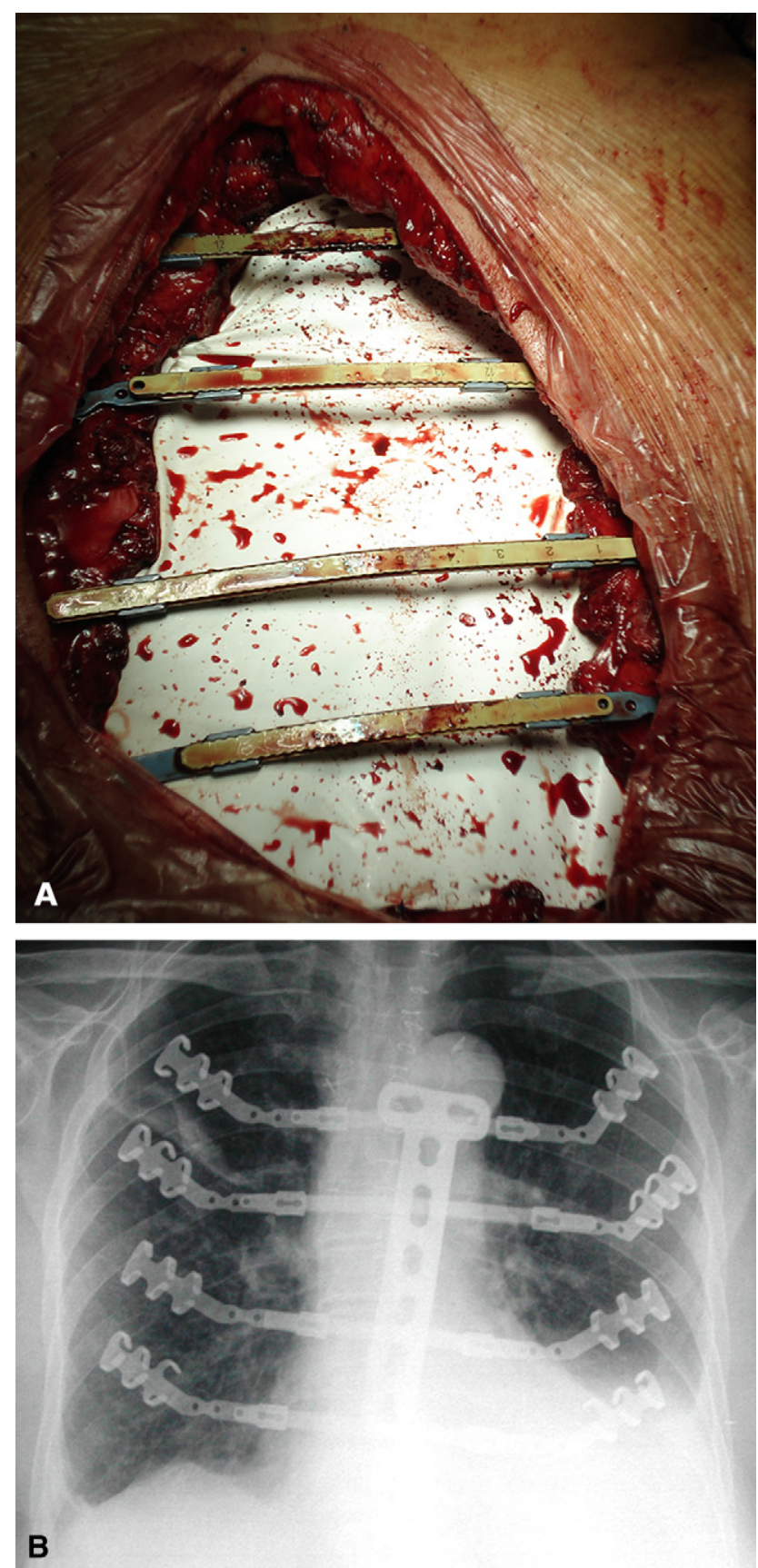

FIGURE 2. A, Intraoperative view of the surgical transverse reconstruction with four moldable titanium bars and rib clips (STRATOS). B, Postoperative radiologic appearance of the final reconstruction with STRATOS for rib replacement and a titanium plate at right angles added for sternal replacement.

ent angles (straight, $45^{\circ}$, or $22.5^{\circ}$ left and right) and connecting bars also available in three lengths $(15 \mathrm{~cm}, 19 \mathrm{~cm}$, and 23 $\mathrm{cm})$. After the ribs were isolated laterally to the margin of resection, the rib clips and the connecting bars were bent to shape (by means of special bending instruments, rib clip fixation, and cutting pliers) and quickly fitted individually in a transverse fashion to reconstruct the sternal area, starting 
from the second rib until the fifth (Figure 2, $A$ ). To provide stability to the bars, we added a multiperforated titanium plate (commonly used for orthopedic implants, not part of the STRATOS) placed at right angles to the bars and wired into each bar by separated stitches passed through the holes of the plate. Finally, we covered the implant with a bilateral pectoralis major muscle flap. After this procedure, the patient was successfully extubated within the first 24 hours and the chest was in stable condition without paradoxical respiration (Figure 2, B). The postoperative period was uneventful and the patient was discharged to rehabilitation 2 weeks afterward. The 6-month follow-up was marked by normal chest $\mathrm{x}$-ray findings and respiratory function test results.

\section{DISCUSSION}

After a wide sternectomy, reconstruction is usually required to restore ventilatory mechanics and to protect the intrathoracic organs. Several methods are available to repair the defect, usually a combination of a prosthesis and coverage with soft tissue (muscle or myocutaneous flap). The most frequently used prosthetic materials are polypropylene nets (Marlex [Davol, Inc, Warwick, RI] or Prolene [Ethicon, Inc, Somerville, NJ]) and PTFE patch. Instead, after a total sternectomy the use of a rigid reconstruction is mandatory and methyl methacrylate is commonly used, spread between two layers of Marlex mesh or on a PTFE patch. However methyl methacrylate is not very easy to handle and, because of its rigidity and solidity, is difficult to adapt to the shape of the patient's chest and to set directly onto bony structures. Furthermore, complications such as the strong risk of infection, dislocation, and fracture of the implant are reported. ${ }^{1-3}$ The utility of titanium bars for sternal reconstruction is described overall in cases of complicated sternal dehiscence after cardiac surgery, whereas their use has been only occasionally reported after subtotal sternectomy for primary tumors. ${ }^{4,5}$ There are no previous reports of a reconstruction after total sternectomy with titanium plates. This system of moldable titanium bars and rib clips (STRATOS), realized for chest wall replacement, allows a firm reconstruction, simple to handle and to attach to the resected edges of the ribs, so that the bars are not easily dislodged. By exploiting the flexibility of the bars and rib clips, the surgeon can model the reconstruction to the specific shape of the chest and of the defect without dead parietal spaces, which are common in "sandwich" reconstructions with methyl methacrylate. The instability of the chest and paradoxical movement are avoided also by anchoring the transverse bars between them with one more plate fixed in a longitudinal fashion. In our opinion, this system broadens the options for reconstruction after total sternectomy.

\section{References}

1. Chapelier A, Macchiarini P, Rietjens M, Lenot B, Margulis A, Petit JY, et al. Chest wall reconstruction following resection of large primary malignant tumors. Eur $J$ Cardiothorac Surg. 1994;8:351-7.

2. Weyant MJ, Bains MS, Venkatraman E, Downey RJ, Park BJ, Flores RM, et al. Results of chest wall resection and reconstruction with and without rigid prosthesis. Ann Thorac Surg. 2006;81:279-85.

3. Incarbone M, Nava M, Lequaglie C, Ravasi G, Pastorino U. Sternal resection for primary or secondary tumors. J Thorac Cardiovasc Surg. 1997;114:93-9.

4. Voss B, Bauernschmitt R, Will A, Krane M, Kröss R, Brockmann G, et al. Sternal reconstruction with titanium plates in complicated sternal dehiscence. Eur J Cardiothorac Surg. 2008;34:139-45.

5. Briccoli A, Manfrini M, Rocca M, Lari S, Giacomini S, Mercuri M. Sternal reconstruction with synthetic mesh and metallic plates for high grade tumours of the chest wall. Eur J Surg. 2002;168:494-9. 